\title{
A dynamic index for managed currencies funds using CME currency contracts
}

\author{
P. LEQUEUX and E. ACAR
}

Banque Nationale de Paris Plc, Dresdner Kleinwort Benson

Banque Nationale de Paris, Dealing Room, 8-13 King William Street, London EC4P 4HS UK

The goal of this paper is to equip the investor with the tools and understanding necessary to evaluate managed currencies' investments in a meaningful way. It is shown that managed currency funds might exhibit a common factor because most of the trading managers use similar technical forecasts to trigger their positions in the financial markets. Therefore, a dynamic benchmark is built, based on technical trading rules. Using the stochastic properties of trading rules, three simple moving averages are selected and given equal weight. Then the basket of trading rules is applied to a set of currencies. The weighting between currencies is done according to volumes traded on the OTC market as observed through Reuters 2000. Such a dynamic benchmark when adjusted for the leverage and risk-free factors exhibits similar performances, namely returns and volatility, to currency traders' benchmarks. The degree of correlation is high and the tracking error is low. These results might have several implications for institutions wishing to consider managed currency funds. First, the dynamic index might be used as a test of market inefficiencies. Second, the technical index might be used as a benchmark for currency trading advisers. As a whole, it can be seen that managed currencies have been trend-followers because the correlation coefficient between the dynamic index and the currency managers is significantly positive. The dynamic index might well be used to distinguish trend-followers from contrarian and judgemental fund. Finally, the dynamic index might be used as a tool to fulfil market expectations. On the one hand, an investor anticipating trending markets might wish to buy the dynamic index. On the other hand, an investor forecasting range-trading markets might wish to sell the index. In sum, the dynamic index might constitute a new financial product, as well as an appropriate benchmark for managed currencies funds.

Keywords: benchmark, currencies, trend, CTA, trading rules

\section{INTRODUCTION}

Over the past two decades, the choice of investment opportunities has grown from 'traditional' instruments such as stocks, bonds and real estate to include mutual funds, hedge funds, foreign securities and managed futures. Futures funds pool investor's money to speculate in futures and currency markets. The buying and selling of futures contracts for futures funds is usually carried out by an independent, outside trading advisor in return for a fee and percentage of profits. In 1996, it was estimated that approximately $\$ 21$ billion was under 
management, compared with $\$ 0.25$ billion in 1980 . The most obvious reason is that professional commodity futures trading advisors (CTA), as a whole, have earned significant profits (Edwards and Park, 1996; McCarthy et al., 1996) for their clients, specially in the inflationary early 1980s. As performance records grew longer and longer, people also discovered that managed futures performed independently of stocks and bonds to such an obvious degree that a new use was found: improving the reward/risk trade-off in diversified investment portfolios (Peters, 1992). However the performances fell far below their 1993 promises in 1994 (Locke, 1994) and only started to recover in 1995. Many investors are still uncertain as to the value of many of these new investment vehicles. An important aspect of investment performances is the predictability of returns over time. If returns are predictable, an investor can select managed futures investments with consistently superior performance. Unfortunately, for individual CTA programmes, there is little evidence of predictability in average returns or in correlations with stocks and bond returns (Irwin et al., 1994).

Therefore, there is a high level of 'fear and misunderstanding' among investors about how managed futures operate. One of the reasons put forward by Schneeweiss (1996) is the apparent lack of a defined systematic risk in the managed futures industry. Individuals have been shown to accept recognized risk if they believe that this risk is also shared by other individuals. Individual risk not shared by others is viewed as unacceptable. A recent survey on managed futures (Intersec Research, 1995) states: 'The importance of a benchmark to institutional investors on both sides of the Atlantic cannot be underemphasized. Most other externally managed asset classes are measured either within universes of like managers or against indices, or both. Many institutional investment decision makers would have difficulty justifying a strategy which could not have the performance of the manager measured in relative terms.' Only $25 \%$ of European users of structured derivatives interviewed by Intersec feel that the available benchmarks are adequate. This may explain why managed futures have not yet gained acceptance as investment vehicles.

The purpose of this article is to show that managed currencies funds may exhibit a common factor in the way they manage their currency exposure. Section 2 introduces the managed currency industry, its techniques and performances. Section 3 briefly recalls the stochastic properties of the trading rules under the random walk assumption. These combined with currency volume, are at the base of the design of the Dynamic Currency Benchmark which is presented in Section 4. Section 5 compares the performances of managed currency funds with such a benchmark and discusses the varied implications for currency investors. The last section summarizes and concludes our results.

\section{MANAGED CURRENCIES FUNDS}

Foreign exchange is the world's largest, most liquid market. Over the past decade, the size of the interbank and derivatives markets has grown dramatically. The success of currencies as an asset class has been seen through the 


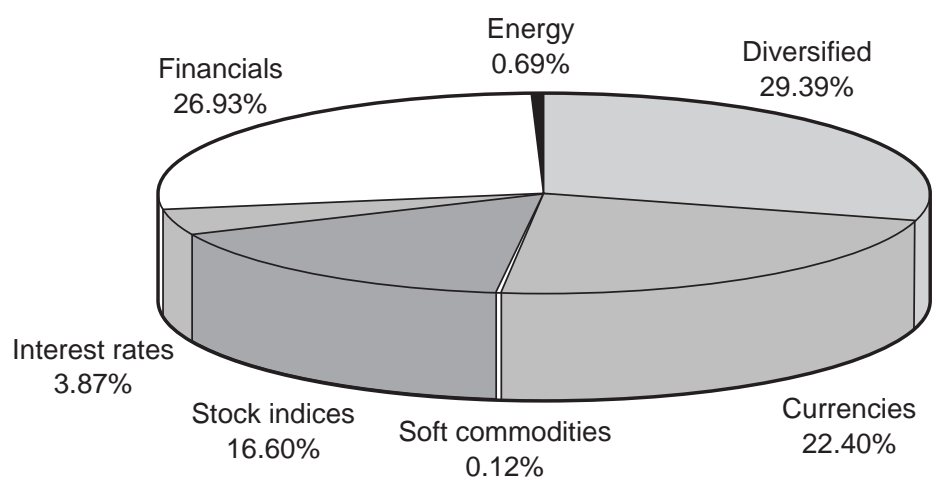

Source: Refco, December 1994

Fig. 1. Sectors traded by the CTAs

ever increasing number of currency funds and currency CTAs made available to the investor. The currency CTA represented in itself $22.4 \%$ of the money under management in December 1994. If we take the assumption that a third of the position managed by the diversified sector is made of currency, we now look at about $32.2 \%$ of the money being managed through the currency market or an estimated $\$ 7$ billion (Fig. 1).

CTAs must report their actual performance records, also known as track records. If a CTA has no past performance, or is using hypothetical performance, this fact must also be disclosed. Ferrell Capital, a risk management company, has created a performance index to provide objective analysis of the firms that trade currencies for outside clients (Parker, 1993). The Ferrell FX Index is equally weighted and represents the average performance of 36 currency programmes. Monthly returns are net of fees and expenses and include interest for each currency advisor. Another currency index has been developed by Tass management, a UK-based independent consultancy that monitors the managed futures industry (Fox-Andrews and Meaden, 1995). The Tass currency index is weighted according to assets under management and is therefore reweighted every month as the asset base of each trader changes. As of 1995, the Tass index included 51 currency programmes. Monthly returns are net of fees and expenses and include interest for each currency advisor.

Because of the nature of the underlying, the currency sector of the managed futures may be in a higher need for a standardized index than the equity or interest rate sector. Indeed whereas most of the other markets have indices to explain their performances and respond to the portfolio analysis needs of the fund manager, very few are available for the currency markets. The available benchmarks do not reflect what is the true yield of the currency market. In fact, most of the currency indices available are either proprietary and not fully transparent or are passive indices and not relevant for dynamic portfolio management purpose. Passive indices do not reflect any of the necessary 
money management skills to generate profit out of the FX markets. An example of that would be the Usdx index. The Usdx parallels the Federal Reserve Board's dollar index. The Usdx measures the change in exchange rates relative to the base period of March 1973. Values are weighted by each country's share of world trade and averaged. Though being a useful instrument for hedging, the Usdx index does not reflect any timing ability. Most of the managed futures investments assume the possibility of being long or short in a financial market in approximately equal frequency (Schwager, 1996). Consequently a passive benchmark such as the USDX would be a poor performance analysis tool to use for monitoring active currency managers.

The Usdx is fairly flat for the overall period January 1987 to July 1995, whereas both the Ferrell and Tass indices display attractive returns despite the losses incurred in 1994 (Fig. 2). One must note that although Tass and Ferrell indices are highly correlated, their mean and volatility substantially differ. Deviations in terms of the maximum drawdown ${ }^{1}$ are even more impressive. There is almost a ratio 3 to 1 between the Tass and Ferrell maximum drawdowns (Table 1). This would be confusing for an investor as these benchmarks are

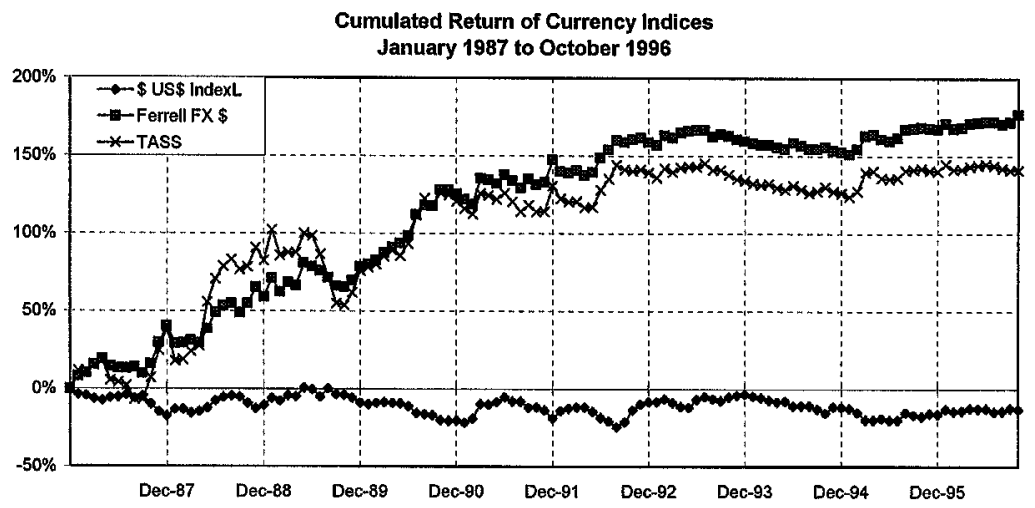

Fig. 2. Currency indices

Table 1. Performance measures of currency indices

\begin{tabular}{lcrc}
\hline & \multicolumn{1}{c}{ USDX } & Ferrell FX & \multicolumn{1}{l}{ TASS } \\
\hline Return & $-1.30 \%$ & $17.99 \%$ & $14.35 \%$ \\
Volatility & $9.37 \%$ & $17.54 \%$ & $26.07 \%$ \\
Return/volatility & -0.14 & 1.03 & 0.55 \\
Maximum drawdown & $-24.99 \%$ & $-15.68 \%$ & $-48.60 \%$ \\
\hline
\end{tabular}

${ }^{1}$ The maximum drawdown here is defined as the maximum loss that an investor would have suffered if he had entered at the worst possible time. 
Table 2. Correlations between currency indices

\begin{tabular}{llll}
\hline & USDX & Ferrell FX & TASS \\
\hline USDX & 1 & & \\
Ferrell FX & -0.13 & 1 & \\
TASS & -0.14 & 0.90 & 1 \\
\hline
\end{tabular}

supposed to reflect the same thing, the performance and risk of the managed currency sector. The lack of transparency and the sensibility to survival bias that certain composite benchmarks in the industry exhibit might be some of the reasons why most of the structured derivative users feel that the available benchmarks are inadequate (Intersec Research, 1995)

The correlation coefficient between the Usdx and the CTAs indices is not significantly different from zero (Table 2). This reflects the poor ability of the USDX to capture the source of profit that the CTAs try to tap through their management skills and techniques.

The reason behind the failure of a passive benchmark to adequately describe currency fund performances lays within the close examination of the managed futures industry. The purpose of this paper is to show that a fully transparent dynamic index which closely replicates the performances of currency managers can be built. Unlike many traditional money managers, there are no restrictions on taking short positions or the ability to sell short unless the asset market first moves up. Therefore, managed currency traders may take both long and short positions depending on market environments. The low transaction costs combined with the ability to go short may permit the use of active strategies to obtain positive returns in markets for which short time periods, may be overvalued. According to Managed Account Reports, most of the money is managed by systematic traders (63\%) and discretionary traders (27\%) who partly back their decision on technical analysis (Fig. 3). Systematic traders primarily rely on trading programmes or models that generate buy and sell

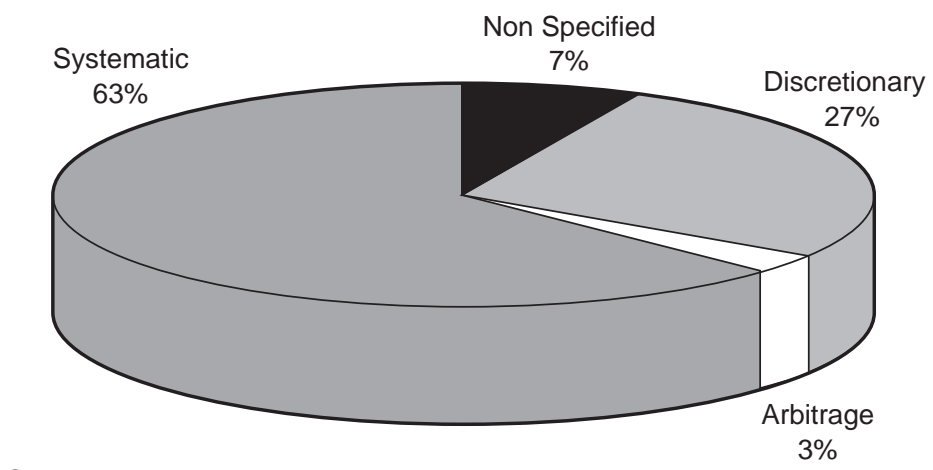

Source: Managed Accounts Reports, March 1993

Fig. 3. CTAs trading styles 
signals. Trades are selected, entered and exited according to such models, not permitting human intervention in the process. Discretionary traders rely on their experience and judgement although they may use some unformalized system or model to backup their trading decisions. It is interesting to note that $70 \%$ of the CTAs are trend followers and tend to trade in a similar manner (Billingsley and Chance, 1996). A better understanding of the performances gathered in a CTA currency index requires a thorough analysis of technical trading rules.

\section{TECHNICAL TRADING RULES}

In the following, we put forward the concepts on which the Dynamic Currency Benchmark design is based. Investors who invest in financial markets are exposed to uncertain price changes. As a risky asset fluctuates in value, the value of the investment containing it may change. One must decide how to redefine the investment in response to such changes. Dynamic strategies are explicit rules for doing so. Dynamic strategies differ from static strategies, such as a buy-and-hold rule, in that trading in the asset occurs throughout the investment horizon, at times and in amounts that depend upon a fixed set of rules and future price changes. Dynamic strategies are developed following the expectations investors have formed about the statistical nature of the price process.

In non-random markets, price change can be predicted. There are market imperfections, such as the existence of serial and volatility dependencies. The goal of dynamic strategies in this case is to exploit these imperfections and to outperform the market. To this end, market timing or forecasting strategies are used. On the one hand, volatility dependencies can be exploited through option strategies such as straddle. On the other hand, serial dependencies are best exploited by directional trading rules.

To be objective, buy and sell signals should be based on data available up to the current time $t$ and should be independent of future information. Using the theory of Markov times, Neftci (1991) shows that the moving average method constitutes such a well-defined methodology. Moreover the simplicity of the trading rules help in giving transparency and replicability to the proposed benchmark. While the existence of market trends has been questioned in academic literature, recent evidence exists that due to institutional factors (i.e. end of month window dressing, portfolio rebalancing, government actions) markets may trend for varying time periods in various markets. Taylor (1990, 1994), Brock et al. (1992), LeBaron (1991, 1992), Levich and Thomas (1993), Silber (1994) have documented the profitability of trend-following rules in markets as different as stock indices, interest rates and currencies. The moving average method has been chosen in this study among an infinite universe of technical indicators because it is the most popular trading rule among futures traders (see, for a recent survey, Etzkorn, 1995).

Therefore this elementary strategy might be able to replicate CTAs trading styles. The simplest rule of this family is the single moving average which says: when the rate penetrates from below (above) a moving average of a given length 
$m$, a buy (sell) signal is generated. If the current price is above the $m$-moving average, then it is left long for the next 24 hours, otherwise it is held short. The rate of return generated by a simple moving average of order $m$ has been calculated as $R_{t}=B_{t-1} X_{t}$ where $X_{\mathrm{t}}=\ln \left(P_{t} / P_{t-1}\right)$ the underlying logarithmic return, $P_{t}$ is the asset price at time $t$, and $B_{t-1}$ is the signal triggered by the trading rule at time $t-1$ defined by:

$$
\begin{aligned}
& B_{t-1}=1 \text { if } P_{t-1}>\frac{1}{m} \sum_{i=1}^{m} P_{t-\mathrm{i}} \text { (long position) } \\
& B_{t-1}=-1 \text { if } P_{t-1}<\frac{1}{m} \sum_{i=1}^{m} P_{t-\mathrm{i}} \text { (short position) }
\end{aligned}
$$

Typical values of length are between 2 and 120. To design a representative basket of trading rules, one may briefly recall some basic properties of trading rules under the random walk assumption including expected return, volatility, transaction costs and correlations between strategies.

\section{Proposition $\mathbf{1}^{2}$}

If the underlying process of returns $\left\{X_{t}\right\}$ follows an iid centred distribution and the rule triggers long and short positions with equal probability, the process of rule returns $\left\{R_{t}\right\}$ follows the same iid centred distribution.

\section{Proposition $2^{3}$}

Assuming that the underlying time series, $X_{t}$ follows a centred iid normal law, the returns $R_{\mathrm{l}, t}$ and $R_{2, t}$ generated by moving averages of order $m_{1}$ and $m_{2}$ exhibit linear correlation coefficient $\rho_{\mathrm{R}}$ given by:

$$
\rho_{\mathrm{R}}\left(m_{1}, m_{2}\right)=\frac{2}{\pi} \arcsin \left(\frac{\sum_{i=0}^{\min \left(m_{1}, m_{2}\right)-2}\left(m_{1}-i-1\right)\left(m_{2}-i-1\right)}{\sqrt{\sum_{i=0}^{m_{1}-2}\left(m_{1}-i-1\right)^{2}} \sqrt{\sum_{i=0}^{m_{2}-2}\left(m_{2}-i-1\right)^{2}}}\right)
$$

Table 3 shows the coefficient correlation between the cash flows triggered by two different moving averages applied to the same underlying market. For instance $\rho[S(5), S(9)]$ means the rule returns correlation between the moving average of order 5 and the moving average of order 9 . Using equation (1), it is equal to 0.705 .

\section{Proposition $3^{4}$}

Assuming that the underlying time series, $X_{t}$ follows a centred iid normal law, the expected number of round turns generated by a moving average method of

\footnotetext{
${ }^{2}$ Proofs of Proposition 1 can be found in Acar (1996).

${ }^{3}$ Proofs of Proposition 2 can be found in Acar and Lequeux (1996).

${ }^{4}$ Proofs of Proposition 3 can be found in the Appendix.
} 
Table 3. Rule correlations

\begin{tabular}{lcccccccc}
\hline$\rho$ & $S(2)$ & $S(3)$ & $S(5)$ & $S(9)$ & $S(17)$ & $S(32)$ & $S(61)$ & $S(117)$ \\
\hline$S(2)$ & 1 & 0.705 & 0.521 & 0.378 & 0.272 & 0.196 & 0.142 & 0.102 \\
$S(3)$ & & & 0.71 & 0.512 & 0.366 & 0.264 & 0.19 & 0.137 \\
$S(5)$ & & & 1 & 0.705 & 0.501 & 0.361 & 0.26 & 0.187 \\
$S(9)$ & & & & 1 & 0.699 & 0.501 & 0.359 & 0.258 \\
$S(17)$ & & & & & 1 & 0.707 & 0.504 & 0.361 \\
$S(32)$ & & & & & & 1 & 0.705 & 0.502 \\
$S(61)$ & & & & & & & 1 & 0.704 \\
$S(117)$ & & & & & & & & 1 \\
\hline
\end{tabular}

order m supposing that a position is opened at the beginning of the period and that the last position is closed at the end day of the period, is:

$$
E(N)=1+(T-2)\left[\frac{1}{2}-\frac{1}{\pi} \operatorname{arc} \sin \left(\rho_{\mathrm{F}}\right)\right]
$$

where

$$
\rho_{\mathrm{F}}=\sum_{i=0}^{m-2}(m-i-1)(m-i-2) / \sum_{i=0}^{m-2}(m-i-1)^{2} \quad \text { if } m \geq 2
$$

Subsequently, the expected transaction costs is:

$E(T C)=-c E(N)$

where $c$ is the trading cost per round turn.

Table 4 indicates under the random walk assumption the expected number of round turns out of a year of 250 days. The last column stipulates the resulting yearly cost in percentage terms for a cost per transaction equal to $c=0.03 \%$. Figure 4 displays transaction costs for various orders of moving averages and costs' levels per transaction.

Table 4. Expected number of transactions and cost under the random walk assumption

\begin{tabular}{lll}
\hline $\begin{array}{l}\text { Moving } \\
\text { average }\end{array}$ & $\begin{array}{l}\text { Expected number of } \\
\text { round turns }\end{array}$ & $\begin{array}{l}\text { Expected yearly cost } \\
\% c=0.03 \%\end{array}$ \\
\hline$S(2)$ & 125.00 & -3.75 \\
$S(3)$ & 92.52 & -2.77 \\
$S(5)$ & 67.40 & -2.02 \\
$S(9)$ & 48.62 & -1.46 \\
$S(17)$ & 34.92 & -1.05 \\
$S(32)$ & 25.46 & -0.76 \\
$S(61)$ & 18.62 & -0.56 \\
$S(117)$ & 13.68 & -0.41
\end{tabular}

* Number of round turns assuming a year of 250 trading days. 


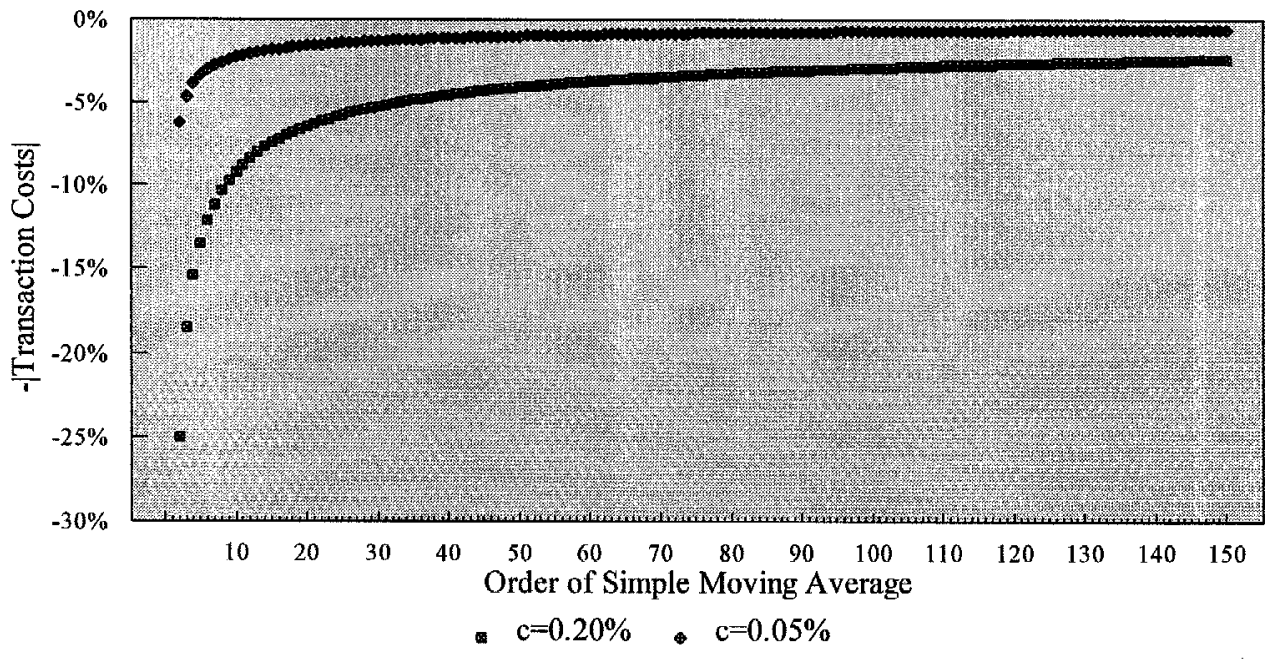

Fig. 4. Expected transaction costs under the random walk assumption

\section{DYNAMIC BENCHMARK}

The FT-Actuaries World indices consortium, by following strict rules in terms of design and maintenance, has designed over 400 indices to service the global investment community (Fox-Andrews and Meaden, 1995). The consortium assesses that benchmarks should be readily replicated in both cash and futures markets, should avoid excessive allocations to illiquid markets, be comprehensive in scope and show positive correlation with the average CTA's returns. In a context of performance measurement investors will require an index which will reflect the sum of portfolios' shares in that market (Bain, 1996). The group recognizes that benchmarks of proprietary nature which are not fully transparent and stable over time are simply not suitable for performance measurement.

Variable number of participants in the tracked universe or for example the addition and withdrawal of track records might generate survival bias (Schneeweiss, 1996) and consequently make a benchmark a poor instrument for performance measurement.

The CAPM states that the systematic risk of an asset should be measured against the 'Market portfolio' made of all the risky assets in the economy, whose weights are determined by their market share. The problem resides in finding a good proxy for this market portfolio. Up to now the evaluation of such a proxy for the currency markets was done by creating composite benchmarks. We demonstrate in the following how a benchmark designed around a basket of currencies timed by trend-following trading rules could provide a good evaluation of the 'market proxy' because of the similarity in the trading approaches used by the currency managers, 'the common factor'. 


\subsection{Market timing}

To avoid choosing an arbitrary parameter as length, we have built an index which includes an equally weighted portfolio of moving averages. The goal of this basket is to adequately represent the time horizons followed by investors while being simple and practical in its design. All investors do not work their strategies over the same time horizons. A day trader can trade anonymously with a pension fund: the former trades frequently for short-term gains, the latter trades infrequently for long-term financial security. Each participates simultaneously and each diversifies with the other. To adequately represent all time horizons, the statistical properties of technical indicators have to be used. Indeed, very little is known about the expected returns generated by trading rules. Expectations widely vary between market participants. Therefore, it was decided to build the index around ex-ante measurable criteria. They are risk reduction and transaction costs.

Orders of the rules have been chosen such that they are almost equicorrelated under the normal random walk assumption (Table 3). Therefore it can be said that the index, including the simple moving averages of order $\{2,3,5,9,17$, $32,61,117\}$, might be representative of CTAs holding periods. Applying equation (1), the correlation is approximately equal to 0.70 . It is possible to measure the risk reduction theoretically achieved by such a portfolio. Indeed, Proposition 1 stipulates that under the random walk assumption, any single moving average when applied on its own bears identical risk, that is the underlying market volatility $\sigma$. On the other hand, a basket of trading rules exhibits a reduced volatility $K \sigma$ where $K$ is the risk reduction coefficient. $K$ is a constant equal to or below 1 depending on the correlation coefficient between trading rules. Following Propositions 1 and 2, the risk reduction coefficient implied by a portfolio of $p$ moving averages of orders $m_{i},\{i=1, \Lambda, p\}$ is given by:

$$
K=\sqrt{p+2 \sum_{i=1}^{p} \sum_{j=i+1}^{p} \rho_{\mathrm{R}}\left(m_{i}, m_{j}\right)} / p
$$

and

$$
\rho_{\mathrm{R}}\left(m_{i}, m_{j}\right) \text { is given by equation (1). }
$$

Using equation (4) our basic index exhibits a risk reduction coefficient equal to $K=0.703$. It may be argued that diversification has not been achieved given the fairly high value of $K$. The basic reason is that trend-following trading rules are by nature positively correlated. Then a meaningful comparison shall refer to the minimum volatility obtainable by a basket of moving averages of order 2 to 120. Using quadratic minimization, the optimal portfolio can be found and is indicated in Fig. 5. One must note that this would exhibit a risk reduction of only $K=0.678$. In addition, optimal weights are unequally distributed. The extreme orders are given the biggest weights (around 25\% each) followed by short-term orders. It can be said that our elementary basket of trading rules achieves satisfactory diversification when compared to a minimum-variance portfolio of moving averages. In addition, from a practitioner point of view, an equally 


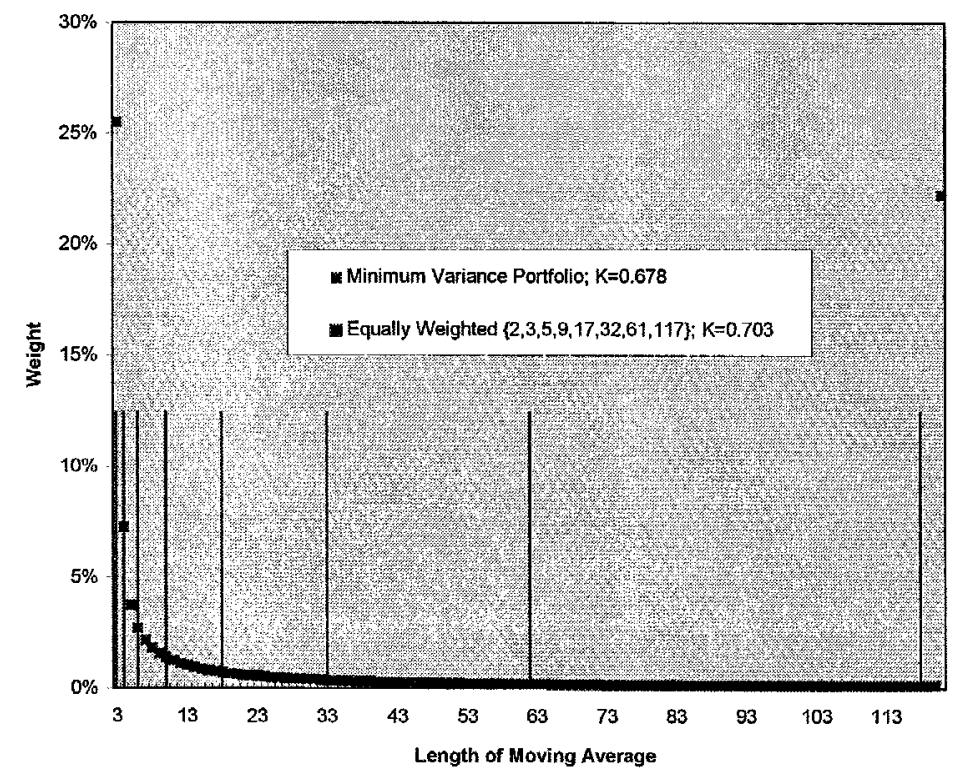

Fig. 5. Portfolio of simple moving averages

weighted portfolio of trading rules is much easier to implement than a minimum variance portfolio involving heavily unbalanced and non-tradable weights.

In order to reflect the cost of operating in the market all the cash flows used in the design of the benchmark have been adjusted for cost of transaction. A conservative estimate in the foreign exchange markets is $-0.03 \%$ per transaction To refine our selection, we decided once again to use the statistical properties of technical indicators. We used the expected number of transactions given by equation (2) for each moving average originally included. We then put a limit of $-1 \%$ yearly return of expected cost as a criterion for selection. This in turn eliminated some of the short-term time horizon that would be too costly to exploit. This left as possible candidates moving averages of order 19 to 120 . Correspondingly, our elementary index $\{2,3,5,9,17,32,61,117\}$ had to be reduced to $\{32,61$ and 117$\}$. The balance between diversification and simplicity is again well achieved by our equally weighted index. This exhibits a risk reduction equal to $K=0.871$ which has to be compared to the minimum achievable from a basket of moving averages of order 19 to $120, K=0.819$.

\subsection{Currency allocation}

The currency weightings have been estimated by looking closely at the volume traded on the OTC market. To evaluate the share of the major currency traded on the foreign exchange market we used statistics on volume shown on the Reuters page DXDX. The data comes from a daily database of prices and volumes traded through Reuters 2000 that covers the period June 1993 to December 1995. The data is reset every day at 22:00 GMT and takes account of 


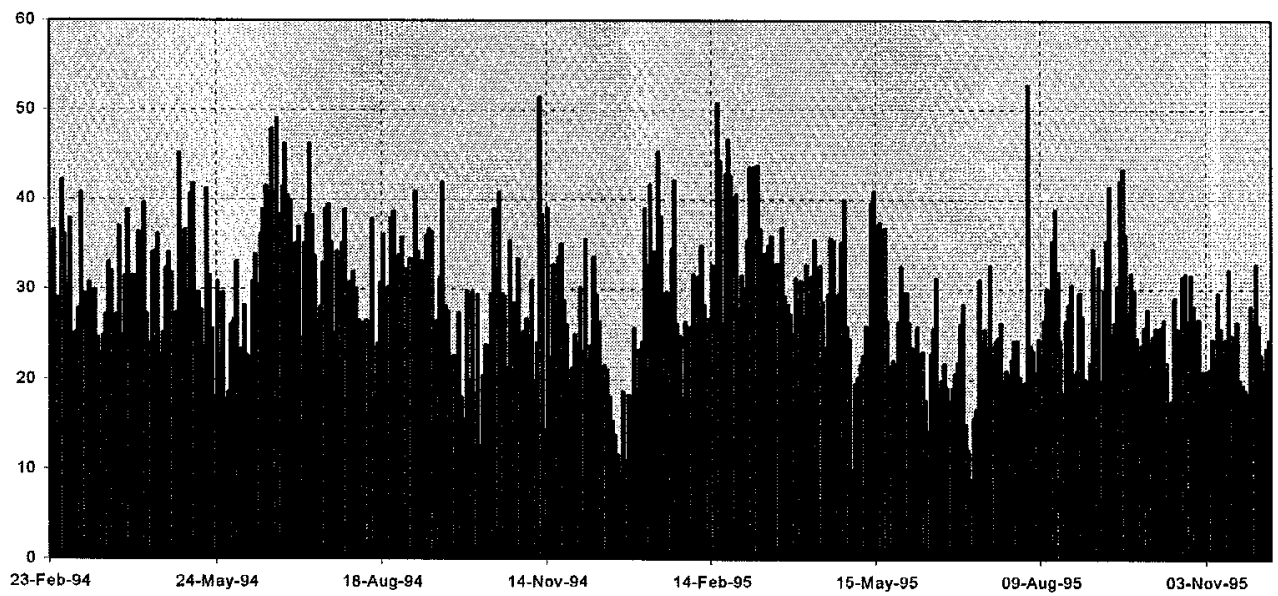

Fig. 6. FX volume traded OTC through Reuters dealing system

only one side of the bargain. Certain banks (Major Swiss and American banks) do not participate in the scheme of providing information on DXDX. Though the information does not reflect the entire market it takes into account the daily volume supplied by a wide spectrum of participants and is thought to be representative of what takes place in the currency market. An average of $\$ 28$ billion is traded every day through the Reuters dealing system (Fig. 6). Even if the volume may be inaccurate, we think that the relative weightings of each currency are meaningful (Table 5 and Fig. 7).

The weight of currency traded is quite stable over time and for that reason we chose to take the average figures for each component in the benchmark in order to have a good representation of the flows that occur in the OTC currency market. However, an easy way to build a fully tradeable, regulated and easily accountable index is to trade futures currency contracts listed on the Chicago Mercantile Exchange (CME), mainly the Dem, Chf, Yen, Gbp and Dem/Yen. Futures contracts are quoted in dollar terms per unit of foreign currency. The Dem/Yen contract is quoted in terms of Yen per unit of Deutschmark. The original weighting displayed in Table 5 had to be changed for two reasons. Firstly, not all currency pairs such as Dem/Chf are traded on the CME. The

Table 5. Summary statistics of volume traded as reported by Reuters

\begin{tabular}{llllllll}
\hline & $\begin{array}{l}\text { Usd/ } \\
\text { Dem }\end{array}$ & $\begin{array}{l}\text { Gbp/ } \\
\text { Usd }\end{array}$ & $\begin{array}{l}\text { Usd/ } \\
\text { Chf }\end{array}$ & $\begin{array}{l}\text { Usd/ } \\
\text { Yen }\end{array}$ & $\begin{array}{l}\text { Dem/ } \\
\text { Yen }\end{array}$ & $\begin{array}{l}\text { Dem/ } \\
\text { Chf }\end{array}$ & $\begin{array}{l}\text { Gbp/ } \\
\text { Dem }\end{array}$ \\
\hline $\begin{array}{l}\text { Average } \\
\text { Standard }\end{array}$ & $40.20 \%$ & $10.85 \%$ & $7.48 \%$ & $22.37 \%$ & $6.41 \%$ & $4.42 \%$ & $8.27 \%$ \\
$\begin{array}{l}\text { Deviation } \\
\text { Weight in index }\end{array}$ & $5.84 \%$ & $2.75 \%$ & $1.81 \%$ & $6.20 \%$ & $2.03 \%$ & $1.69 \%$ & $4.10 \%$ \\
\hline
\end{tabular}




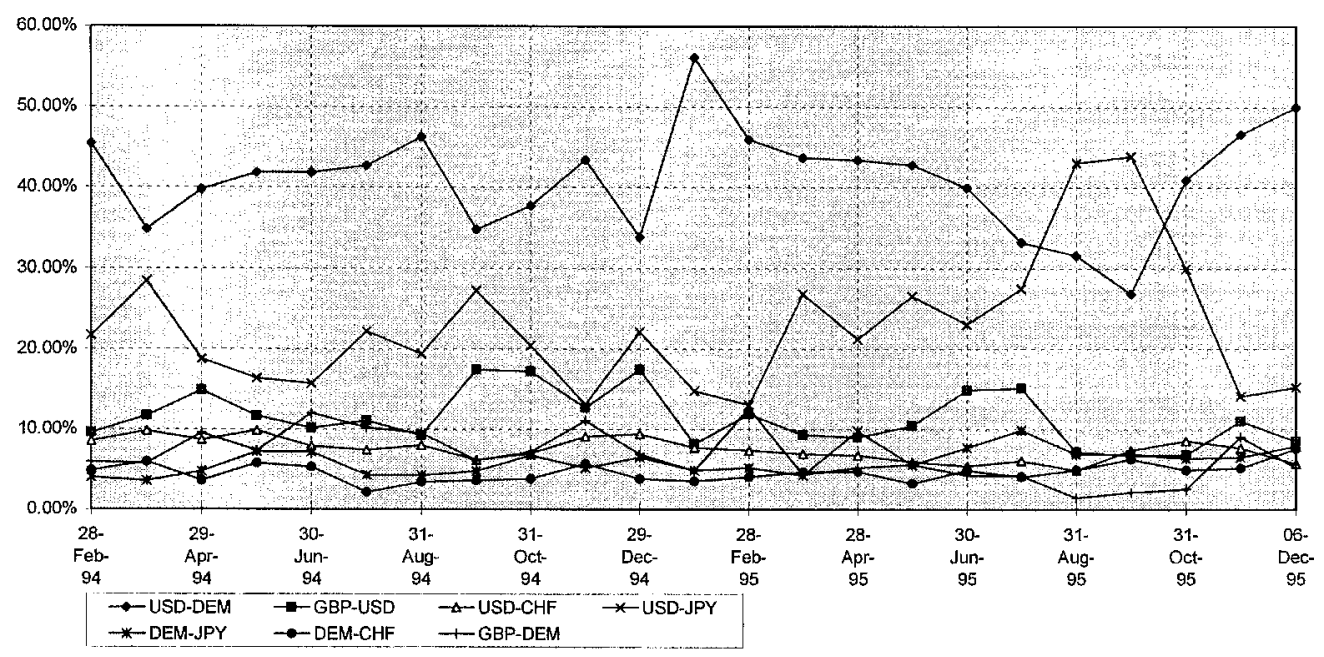

Fig. 7. Evolution of the FX volume traded OTC per currency

missing cross-futures contracts have been recreated using dollar-based currencies. On the one hand, selling one Dem contract and buying one Chf will replicate a short position in Dem against Chf. On the other hand, buying one Dem contract and buying one Gbp contract will not, strictly speaking, replicate a long position in Gbp against the Usd. This is due to the fact that both contracts do not have the same face value. Therefore, it must be underlined that in what follows $\mathrm{Gbp} / \mathrm{Dem}$ will always refer to its approximated substitute using a dollar-based contract. Secondly, the contracts have a fixed face value which cannot be split up. Nevertheless, as can be seen from Table 6 we can create a basket that stays within one standard deviation of the average volume traded on the OTC markets.

Each currency is traded using the equally weighted basket of moving averages previously described: S(32), S(61), S(117). The weighting per currency and

Table 6. Currency allocation

\begin{tabular}{lrrrrrrrrr}
\hline Currency & Original & \multicolumn{1}{c}{ Notional } & Spot & \multicolumn{1}{c}{ Notional } & \multicolumn{2}{c}{ Total \$ } \\
\$em & $40.20 \%$ & 125000 & 1.4365 & 87017 & 18 & 1566307 & $35.85 \%$ & $-4.35 \%$ \\
Yen & $22.37 \%$ & 12500000 & 103.92 & 120285 & 9 & 1082564 & $24.78 \%$ & $2.41 \%$ \\
Chf & $7.48 \%$ & 125000 & 1.1585 & 107898 & 3 & 323694 & $7.41 \%$ & $-0.07 \%$ \\
Gbp & $10.85 \%$ & 62500 & 1.5542 & 97138 & 6 & 582825 & $13.34 \%$ & $2.49 \%$ \\
Dem/Yen & $6.41 \%$ & 125000 & 72.34 & 87017 & 3 & 261051 & $5.98 \%$ & $-0.43 \%$ \\
Dem/Chf* & $4.42 \%$ & 125000 & 1.44 & 87017 & 3 & 261051 & $5.98 \%$ & $1.56 \%$ \\
Gbp/Dem & $8.27 \%$ & 62500 & 1.5542 & 97138 & 3 & 291413 & $6.67 \%$ & $-1.60 \%$ \\
Total & & & & & & 4368905 & $100 \%$ & \\
\hline
\end{tabular}

${ }^{*}$ Synthetic cross using dollars contracts 


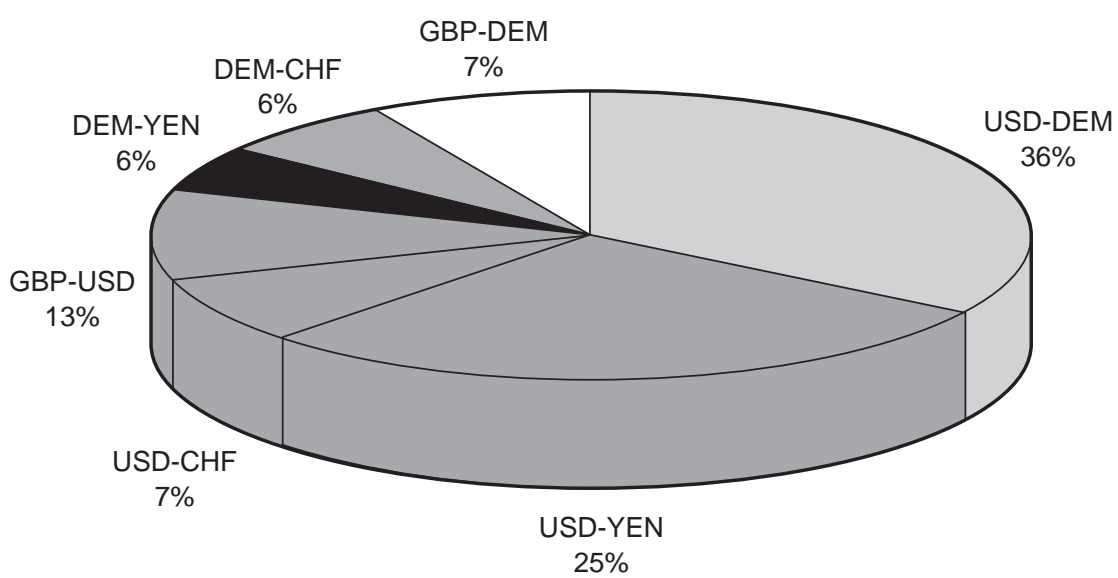

Fig. 8. Currency allocation

trading rules is specified in Fig. 8 and Table 7 as number of contracts. This means for instance that if $\mathrm{S}(32)$ and $\mathrm{S}(61)$ are long Gbp against the Usd but $\mathrm{S}(117)$ is short, the overall position is long $2=2+2-2$ Gbp contracts.

\section{A COMPARISON WITH MANAGED CURRENCY FUNDS}

To make meaningful the comparison between the dynamic benchmark and the average currency funds in terms of correlation, tracking error and Sharpe ratio, two adjustments had to be made.

Firstly, it is known that managed currency funds gear their positions. Therefore leverage can and must be given to the dynamic benchmark. We will use a notional value for our contract of USD 1.5 Million which implies a leverage of 2.91. The reason for doing so is that the resulting dynamic index generates now a volatility of $21.72 \%$ which is in line with the Tass and Ferrell indices. Secondly, both the Ferrell and Tass indices include the risk-free return earned on the asset under management. Similarly, we added the return generated by the holding of a US T-Bill one month to each of our monthly returns.

Table 7. Dynamic Index Allocation

\begin{tabular}{|c|c|c|c|}
\hline \multicolumn{4}{|c|}{ Currency/Rules } \\
\hline & $S(32)$ & $S(61)$ & $S(117)$ \\
\hline Dem & 6 & 6 & 6 \\
\hline Yen & 3 & 3 & 3 \\
\hline Chf & 1 & 1 & 1 \\
\hline Gbp & 2 & 2 & 2 \\
\hline Dem/Yen & 1 & 1 & 1 \\
\hline Dem/Chf & $1 \mathrm{Usd} / \mathrm{Dem}+1 \mathrm{Usd} / \mathrm{Chf}$ & $1 \mathrm{Usd} / \mathrm{Dem}+1 \mathrm{Usd} / \mathrm{Chf}$ & $1 \mathrm{Usd} / \mathrm{Dem}+1 \mathrm{Usd} / \mathrm{Chf}$ \\
\hline Gbp/Dem & $1 \mathrm{Gbp} / \mathrm{Usd}+1 \mathrm{Usd} / \mathrm{Dem}$ & $1 \mathrm{Gbp} / \mathrm{Usd}+1 \mathrm{Usd} / \mathrm{Dem}$ & $1 \mathrm{Gbp} / \mathrm{Usd}+1 \mathrm{Usd} / \mathrm{Dem}$ \\
\hline
\end{tabular}


Table 8. Performance Measures of Currency Funds

\begin{tabular}{lccc}
\hline & Ferrell FX & FXDX + TB & TASS \\
\hline Return & $17.99 \%$ & $18.08 \%$ & $14.35 \%$ \\
Volatitlity & $17.54 \%$ & $19.75 \%$ & $26.07 \%$ \\
Return/volatility & 1.03 & 0.92 & 0.55 \\
Maximum drawdown & $-15.68 \%$ & $-18.83 \%$ & $-48.60 \%$ \\
\hline
\end{tabular}

Table 8 shows that the adjusted dynamic benchmark now exhibits return, volatility, Sharpe ratio (see also Figs 9 and 10) and maximum drawdown comparable to currency managers. Results are even more spectacular in terms of tracking error and correlation (Figs 11 to 14). The tracking error is here

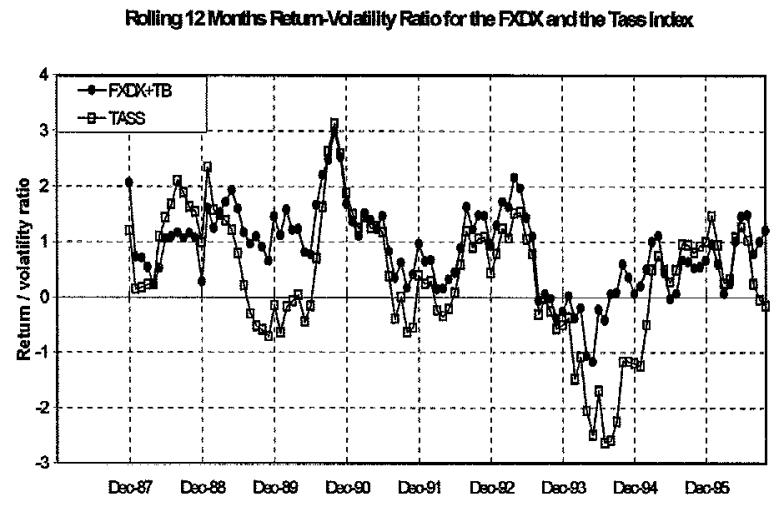

Fig. 9. Sharpe ratio versus Tass

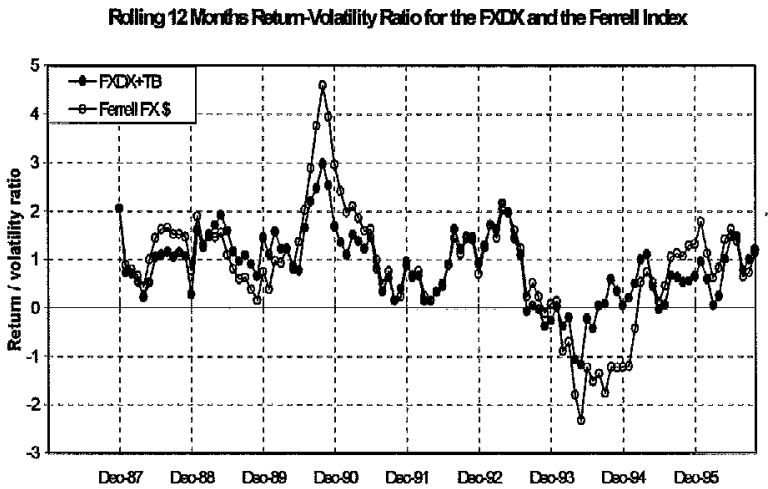

Fig. 10. Sharpe ratio versus Ferrell 


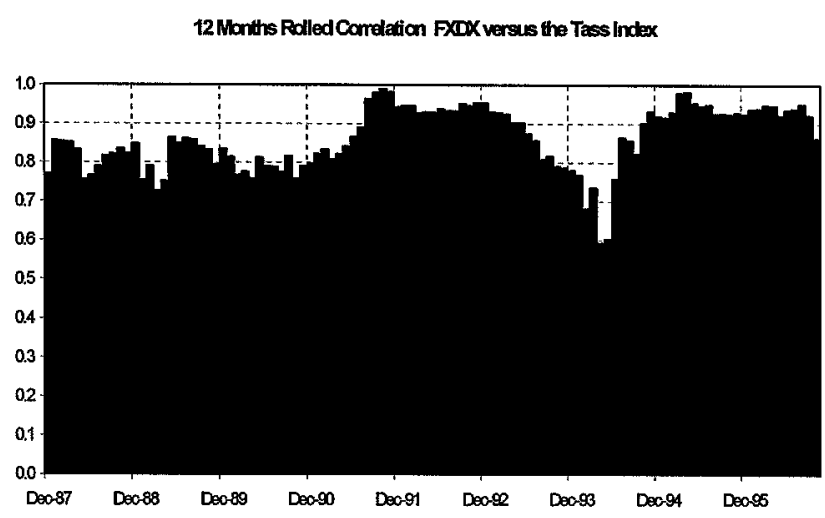

Fig. 11. Correlation with Tass

defined as the relative performance of the currency manager index to the benchmark. The fairly high tracking error with the Tass and Ferrell indices between 1987 and 1991 may be due to the small number of currency CTAs at that time. For instance the universe of CTAs included in the Ferrell index has grown from nine in 1987 to 36 in 1997.

These results might have several implications for institutions wishing to consider managed currency funds. First, the dynamic index might be used as a test of market inefficiencies. It may detect trends and therefore opportunities for profits. The currency market was clearly trending from 1987 to 1993 as witnesses the profitability of the dynamic index. Second, the technical index might be used as a benchmark for CTAs. As a whole, it can be seen that managed currencies have been trend-followers because the correlation coefficient between the dynamic index and the currency managers is significantly positive. This may have been less the case for the year 1994 because of losses incurred from March 1993 by systematic traders due to range-trading markets. Therefore,

12 Months Rolled Correlation FXXX versus the Ferrell Index

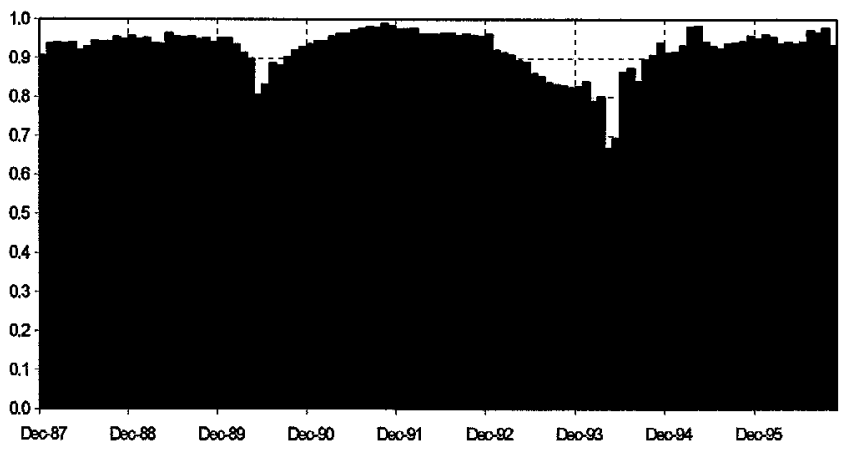

Fig. 12. Correlation with Ferrell 


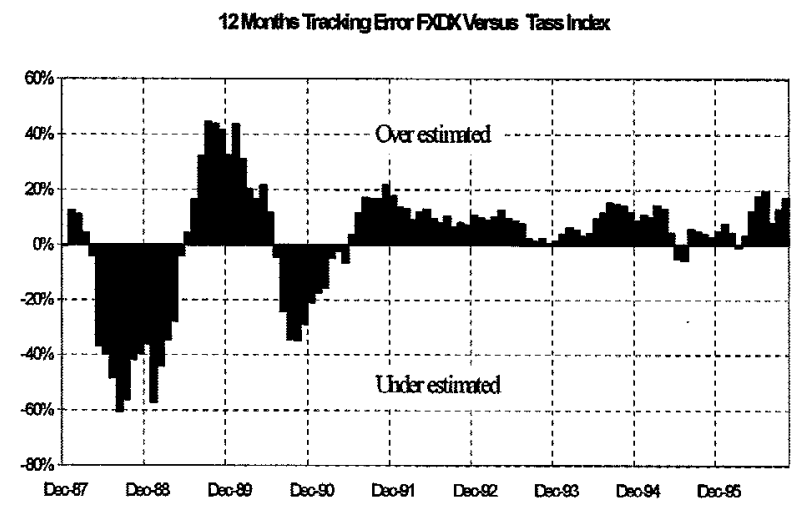

Fig. 13. Tracking error versus Tass

some CTAs might have considered changing their trading strategies and even become contrarian. The dynamic index might therefore be used to distinguish trend-followers (high positive correlation with the dynamic index) from contrarian (negative correlation) and judgemental fund managers (zero correlation). An example of this point is illustrated by Fig. 15. It can be seen that the currency trader who qualifies himself as a trend-follower is indeed significantly positively correlated with the benchmark. On the other hand, the discretionary trader exhibits far less correlation with the technical benchmark.

Finally, the dynamic index might be used as a tool to fulfil market expectations. On the one hand, an investor anticipating trending markets might wish to buy the dynamic index. On the other hand, an investor forecasting range-trading markets might wish to sell the index. The dynamic index is designed to exploit directional forecasts. This may therefore constitute a complementary financial product to options strategies which have as their main purpose exploitation of anticipated volatility. Our index captures trading advisors' styles and is easier to

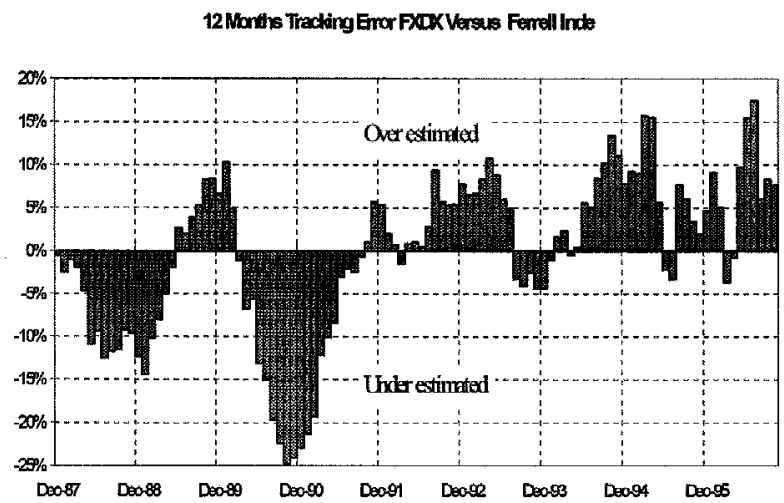

Fig. 14. Tracking error versus Ferrell 


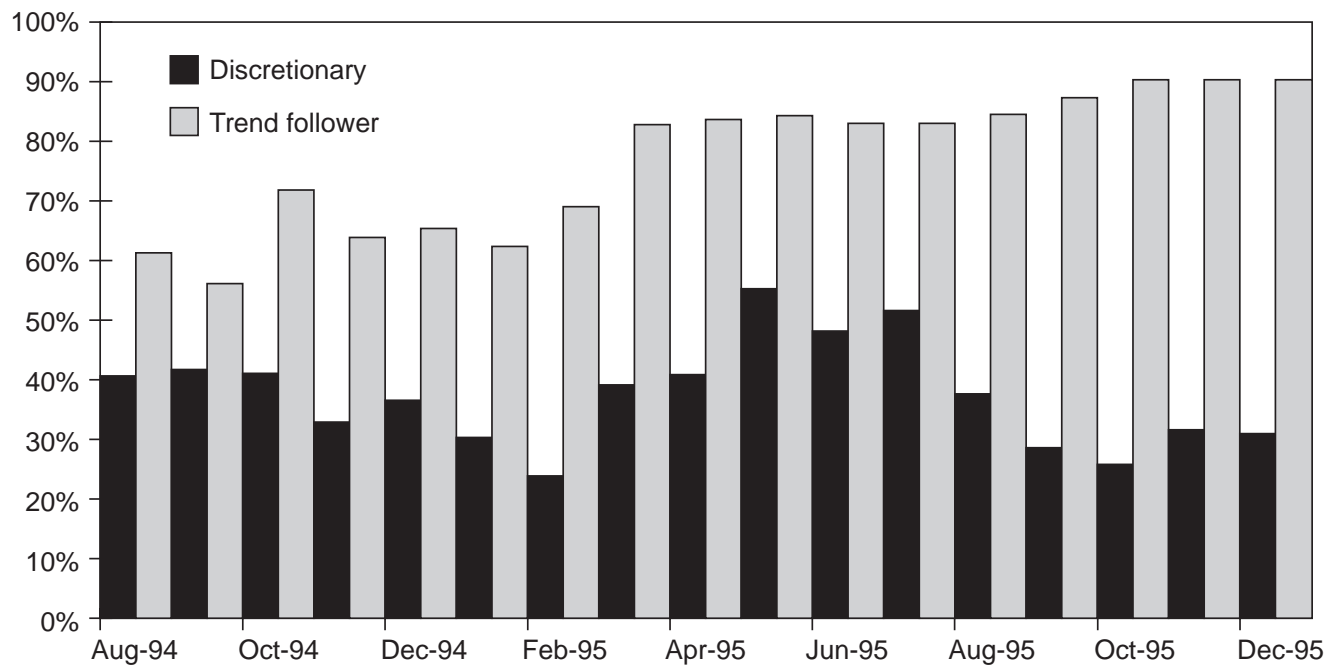

Fig. 15. Correlation of trend-follower and discretionary CTA with the currency benchmark

understand because investors know the index components. In sum, the dynamic index might constitute a new financial product, as well as an appropriate benchmark for managed currencies funds.

\section{CONCLUSIONS}

The goal of this paper has been to propose a new dynamic benchmark which replicates to a high degree of correlation and risk/reward profile the average performance of the actively managed currency funds. To do so, a portfolio of technical indicators applied to a set of currencies was designed using the stochastic properties of trading rules and observed currency volumes. Returns generated by such a benchmark when adjusted by the leverage and risk-free factors move well in line with the actively managed currency funds. The results might have several implications for institutions who wish to actively manage currencies. They may directly invest in the benchmark. Another alternative is to use the benchmark to analyse currency manager performances. In both cases, it is hoped that such a benchmark can improve the understanding of managed currency investments.

\section{APPENDIX: PROOFS OF PROPOSITION 3}

\section{Proposition 3}

The expected number of round turns following a linear rule under the Gaussian process without drift assumption is now established. Again results extend to nonlinear forecasters assuming they asymptotically follow a normal law.

The average duration of a position triggered by a technical indicator is difficult to establish because it involves truncated multivariate probabilities 
analytically unknown. An easier step is to determine the probability that there occurs a reversal of position a given day, noted $P$ [reversal].

A reversal of position on day $t$ means that the signal triggered by the trading rule are of opposite signs on days $t-1$ and $t$. Since the underlying process is symmetrical:

$$
\begin{aligned}
& P[\text { reversal }]=P\left[F_{t-1}<0, F_{t}>0\right]+P\left[F_{t-1}>0, F_{t}<0\right]=2 P\left[F_{t-1}<0, F_{t}>0\right] \\
& P[\text { reversal }]=2[0,0](-\rho)
\end{aligned}
$$

where $\rho=\operatorname{Corr}\left(F_{t-1}, F_{t}\right)$, and $[0,0]$ is the bivariate truncated probability given by Johnson and Kotz (1972). It results that:

$$
P[\text { reversal }]=\frac{1}{2}-\frac{1}{\pi} \operatorname{arc} \sin (\rho)
$$

Then the expected number of transactions over a period of $T$ days is:

$$
E(N)=T\left[\frac{1}{2}-\frac{1}{\pi} \operatorname{arc} \sin (\rho)\right]
$$

If we assume that a position is taken on the first day of the period and there cannot be any new position on the last day (close of position), there are in fact $T-2$ days over which a stochastic position can be triggered. Then a slight adjustment to the previous formula must be made:

$$
E(N)=1+(T-2)\left[\frac{1}{2}-\frac{1}{\pi} \arcsin (\rho) \quad \text { for } T \geq 2\right.
$$

\section{REFERENCES}

Acar, E. (1996) Expected returns of directional forecasters, Working Paper, BNP.

Acar, E. and Lequeux, P. (1995) Trading rules profits and the underlying time series properties, First International Conference on High Frequency Data in Finance: Zurich, Switzerland.

Acar, E. and Lequeux, P. (1996) Dynamic strategies, a correlation study, in C. Dunis (ed.) Forecasting Financial Markets, Wiley, pp. 93-123.

Bain, G. (1996) Investment Performance Measurement, Woodhead.

Billingsley, R. and Chance, D. (1996) Benefits and limitations of diversification among commodity trading advisors, The Journal of Portfolio Management, Fall, 65-80.

Brock, W., Lakonishok, J. and LeBaron, B. (1992) Simple technical rules and the stochastic properties of stock returns, Journal of Finance, 47, 1731-1764.

Edwards, F. and Park, J. (1996) Do managed futures make a good investment?, The Journal of Futures Markets, 16, 475-517.

Etzkorn, M. (1995) Getting an indication, Futures, February, 38-39.

Fox-Andrews, M. and Meaden, N. (1995) Derivatives Markets and Investment Management', Woodhead Faulkner.

InterSec Research Corporation (1995) Press Release Structured Derivatives Survey, April, pp. 1-3.

Irwin, S.H., Zulauf, C.R. and Ward, B.W. (1994) The predictability of managed futures returns, The Journal of Derivatives, Winter, 20-27.

LeBaron, B. (1991) Technical trading rules and regime shifts in foreign exchange, University of Wisconsin, Social Science Research, Working Paper 9118.

LeBaron, B. (1992) Do moving average trading rule results imply nonlinearities in foreign exchange markets, University of Wisconsin, Social Science Research, Working Paper 9222 . 
Levich, R.M. and Thomas, L.R. (1993) The significance of technical trading-rule profits in the foreign exchange market: a bootstrap approach, Journal of International Money and Finance, 12, 451-474.

Locke, J. (1994) Future tense, Risk Magazine, July, 42-45.

McCarthy, D., Schneweiss, T. and Spurgin, R. (1996) Investment through CTAs: an alternative managed futures investment, The Journal of Derivatives, Summer, $36-47$.

Neftci, S.N. (1991) Naive trading rules in financial markets and Wiener-Kolmogorov prediction theory: a study of 'technical analysis', Journal of Business, 64, 549-571.

Parker, V. (1993) Profiting from diversified managed currency strategies: an investor's perspective, in A.W. Gitlin (ed.), Strategic Currency Investing, Probus Publishing, London, pp. 217-259.

Peters, C.C. (1992) Managed Futures: Performance, Evaluation and Analysis of Commodity Funds, Pools and Accounts, Probus Publishing, Chicago.

Schwager, J. (1996) Managed Trading: Myths \& Truths, Wiley \& Sons, New York.

Schneeweiss, T. (1996) The benefits of managed futures. Preliminary Summary Report granted by the European Managed Futures Association.

Schneeweiss, T., Spurgin, R. and McCarthy, D. (1996) Survivor bias in commodity trading advisor performance, The Journal of Futures Markets, 16, 757-772.

Silber, W. (1994) Technical trading: when it works and when it doesn't, The Journal of Derivatives, Spring, 39-44.

Taylor, S.J. (1990) Profitable currency futures trading: a comparison of technical and time-series trading rules, in L.R. Thomas (ed.), The Currency Hedging Debate, IFR Publishing, London, pp. 203-239.

Taylor, S.J. (1994) Trading futures using the channel rule: a study of the predictive power of technical analysis with currency examples, Journal of Futures Markets, 14, 215-235. 